\title{
Cross-Infection Experiments of Psittacanthus schiedeanus: Effects of Host Provenance, Gut Passage, and Host Fate on Mistletoe Seedling Survival
}

\author{
María Magdalena Ramírez and Juan Francisco Ornelas, Departamento de Biología Evolutiva, Instituto de Ecología, A.C., Carretera
} Antigua a Coatepec No. 351, El Haya, Xalapa, Veracruz 91070, México

\begin{abstract}
Ramírez, M. M., and Ornelas, J. F. 2012. Cross-infection experiments of Psittacanthus schiedeanus: Effects of host provenance, gut passage, and host fate on mistletoe seedling survival. Plant Dis. 96:780-787.

Host-specific race formation has been suggested for mistletoe species using cross-dispersal experiments. Here, we tested the effects of host provenance, bird gut passage, and host fate on Psittacanthus schiedeanus seed either manually extracted or bird gut-passed on four host species in Veracruz, Mexico: Acacia pennatula, Liquidambar styraciflua, Platanus mexicana, and Quercus germana. Both groups of seed were placed on the branches of host trees in a full factorial design of cross-inoculation. Bird gut passage had no effect on seed germination, and the only factor having a significant effect on seed germination was host provenance. Results of seedling establishment were similar to those of seed germination, where mistletoe seed inoculated on $P$. mexicana were more likely to germinate and seedlings to establish than

seed inoculated on the other hosts. The significant host provenancefruit treatment interaction was largely due to a lower seedling establishment of gut-passed seed from P. mexicana to P. mexicana and the other hosts. Although host provenance of mistletoe seed was a significant predictor in germination and seedling establishment, the host provenance-host fate interaction was the only significant predictor for seedling survival. The significant host provenance-host fate interaction was largely due to higher survival success of mistletoe seed from $L$. styraciflua to $L$. styraciflua and $P$. mexicana and from $P$. mexicana to $P$. mexicana and a lower success from $Q$. germana to $Q$. germana and from A. pennatula to A. pennatula.
\end{abstract}

The genus Psittacanthus (Loranthaceae) is a New World aerial hemiparasite distributed from Mexico to Argentina on a wide range of angiosperm and gymnosperm hosts (15). In contrast to other mistletoe, genus Psittacanthus is distinguished by its large and conspicuous-red, yellow, or orange flowers; the bulky haustorial connections to the host trees; and the large, lipid-rich fruit which lack endosperm $(5,15,22)$. In his recent monographic treatment of the genus, Kuijt (15) recognized 11 species of Psittacanthus for Mexico: Psittacanthus angustifolius Kuijt, P. auriculatus Eichler, $P$. breedlovei Kuijt, P. calyculatus G. Don, P. macrantherus Eichler, P. mayanus Standl. \& Steyerm., P. palmeri (Watson) Barlow \& Wiens, P. ramiflorus G. Don, P. rhynchanthus (Benth.) Kuijt, P. schiedeanus (Schlecht. \& Cham.) G. Don, and P. sonorae (Watson) Kuijt.

The parrot-flower mistletoe species of the genus Psittacanthus are considered to be the most damaging pathogens to attack commercially important coniferous and other hardwood timber stands throughout Mexico (51). More than 50 genera of angiosperms and conifers have been reported as hosts of Psittacanthus spp. in Mexico, as well as several non-native plant genera (51). The most common Psittacanthus spp. reported on conifers (Pinus and Abies spp.) are $P$. angustifolius and $P$. macrantherus $(14,15,26)$. In arid environments and lowland, tropical deciduous forests, $P$. sonorae, $P$. rhynchanthus, and $P$. palmeri almost exclusively parasitize Bursera spp., and $P$. auriculatus and $P$. breedlovei are most commonly found on Acacia spp. (15). However, the remaining Psittacanthus

Corresponding author: J. F. Ornelas,

E-mail: francisco.ornelas@inecol.edu.mx

Accepted for publication 12 January 2012.

http://dx.doi.org/10.1094/PDIS-06-11-0509

(C) 2012 The American Phytopathological Society spp. in Mexico often use more than one species of host $(5,15,21,22)$. Despite the negative economic impact of some species on valuable crops and forest products, parrot-flower mistletoe species are ecologically important in forest ecosystems because they provide food, cover, and nesting sites for a variety of birds, mammals, and insects $(26,52)$. Coevolutionary relationships with birds (involving pollination and seed dispersal) have fueled several adaptive radiations, thus producing one of the most diverse and fascinating life forms on our planet (52).

Most fruit of mistletoe (Loranthaceae) frequently depend on frugivorous birds for seed dispersal $(3,42,43,52)$, and their spatial, often aggregated, distribution patterns within and between hosts are strongly influenced by the behavior of seed dispersers $(25,42,43)$. Birds either swallow mistletoe fruit whole, remove the outer exocarp and ingest the seed and viscin, or eat only the viscin coating around the seed (26). Once the bird has ingested the seed, it is either regurgitated and dropped or wiped on a branch, or defecated; however, the seed is still covered with some of the viscin coat, which allows it to adhere to potential hosts (18). Although mistletoe seed germinate readily in almost all situations $(13,17,53)$, seed must be freed of the exocarp and deposited by birds on the branches of susceptible host trees to have any chance of establishing $(7,18,23,34,38,41,44)$. Successful mistletoe establishment appears best on fast-growing narrow branches $(32,49,54)$ and certain parts of a host tree $(19,23,33)$. This means that behavioral aspects of birds as well as specific characteristics of host trees likely affect seed deposition and early survival and establishment of mistletoe seedlings $(3,10,16,21,31,46,53)$. Studies that have evaluated seed and seedling survival of mistletoe on different hosts are focused on the examination of seed shadows and infection patterns associated with seed dispersal by frugivorous birds $(4,21,24,25,28,31$, $32,41,46,47)$. The seed rain generated by seed-dispersing birds primarily affects seed movement and propagule distribution, which is one of the determinants of colonization among available host patches at a local scale (2). Likewise, host trees might vary in 
susceptibility to mistletoe infection and, hence, adaptation of mistletoe to the local host can occur $(34,44,46)$. In this way, depending on the heterogeneity of host patches at a local scale, some mistletoe species can develop more specificity on particular host trees $(1,6,9,18,27,34,36,37)$ that may lead to gene flow changes and the eventual formation of mistletoe races $(12,30,37)$. The other component of seed dispersal effectiveness besides seed deposition patterns is the capacity of seed to germinate after ingestion of avian frugivores. Avian dispersers with different fruit-processing mechanisms can affect patterns driven through vectormistletoe interactions or those through host-mistletoe interactions (48) but the effects of gut passage on seed germination are poorly known $(18,29,38,45,50)$.

Integrating these observations, Lara and collaborators (18) hypothesized that mistletoe establishment of species using more than one species of host is likely to be influenced by a combination of factors, including the effects of (i) the avian disperser behavior, (ii) their seed dispersing (by sticking to the bill or body) and processing mechanisms (guts), (iii) the origin of the fruit consumed (host provenance), and (iv) the infection susceptibility of the host tree species where seed were deposited (host fate). Here, we tested the effects of these factors in P. schiedeanus, a Mesoamerican parrotflower mistletoe. For the purpose of our study, we followed the definition of Lara and collaborators (18) of "host provenance" as the host tree species from which the mistletoe fruit were eaten by a bird, and "host fate" as the host tree species where the seed of the mistletoe fruit consumed were deposited. In a previous seed-inoculation experiment, López de Buen and Ornelas (23) evaluated whether post-dispersal processes of $P$. schiedeanus seed vary among host species so as to explain mistletoe host specialization at the regional scale. The experiment was conducted on branches of the study host species and mistletoe seed fate was monitored from seed inoculation to plant survival; however, the source of the mistletoe seed used in inoculation from the main host species compromised questions about host local specificity. Here, we tested experimentally the effects of host provenance, gut passage, and host fate on seed germination, seedling establishment, and seedling survival of $P$. schiedeanus seed either manually extracted or gutpassed by Grey Silky-flycatchers (Ptilogonys cinereus) in four host species of a cloud forest in central Veracruz, Mexico. Our study was aimed at addressing the following specific questions: (i) does seed passage through avian guts affect germination, establishment, and survival of inoculated seed (ii) is the success of germination, establishment of seed, and survival of seedlings affected by host provenance and host fate? A cross-inoculation approach to the study of host specificity by generalist mistletoe is likely to reveal the mechanisms that control mistletoe-host compatibility and the understanding of the mechanisms related to host specificity would shed light on applications to mistletoe control (26), particularly the effects of host provenance and host fate on the development of host resistance and colonization of new host species.

\section{Materials and Methods}

Study area. Fieldwork was conducted from December 2005 to August 2007 in La Pitaya, Coatepec $\left(19^{\circ} 30^{\prime} \mathrm{N}, 96^{\circ} 57^{\prime} \mathrm{W}\right.$, at 1,381 $\mathrm{m}$ above sea level), a suburban area with remnants of gallery forest and cloud forest near the city of Xalapa, Veracruz, Mexico. The region is characterized by frequent and prolonged immersion within orographic clouds. Climate is mild and humid throughout the year, with a dry-cold season from November to March. Most common tree species in the area are parasitized by the mistletoe Psittacanthus schiedeanus (Loranthaceae) (21).

The parasite. P. schiedeanus (Schlecht. \& Cham.) G. Don (parrot-flower mistletoe) is a shrubby (up to $3 \mathrm{~m}$ in height) hemiparasite distributed along the eastern rim of the Sierra Madre Oriental between 1,000 to $1,800 \mathrm{~m}$ above sea level in Mexico to Panama. It parasitizes tall trees in evergreen montane forests (15). Throughout its geographic range, it parasitizes branches of more than 20 native and introduced host tree species $(5,21)$. In central Veracruz, the most severe infections occur on Liquidambar styraciflua $(21,23)$ but no further information on the kind of damage or estimates of economic losses associated with mistletoe is available for this or for the other host species in the study area. The nectar-producing (3.6 to $7.2 \mathrm{mp}$ of sugar per flower per day), self-compatible, orange-yellow flowers of $P$. schiedeanus remain open for approximately 6 days in the study area (39). Several hummingbird species (Atthis heloisa, Amazilia beryllina, A. tzacatl, A. cyanocephala, Campylopterus curvipennis, Lampornis amethystinus, and Lamprolaima rhami), parrots (Pionus senilis), flowerpiercers (Diglossa baritula), butterflies, and bees have been observed visiting flowers of Psittacanthus schiedeanus in the study region (39). Flowers mature into fleshy fruit that change in color from green when immature to purplish-black at ripening. Ripe fruit average 13.8 by $9.5 \mathrm{~mm}$ and contain one seed which weighs, on average, $335 \mathrm{mg}$. Fruit ripening occurs asynchronously from November to April (22). Fruit are consumed and dispersed by a variety of birds; the most frequently observed are Bombycilla cedrorum, Ptilogonys cinereus, and Myiozetetes similis (21-23,38).

The hosts. Our study focused on the four most frequent native host tree species of Psittacanthus schiedeanus with high prevalence values in central Veracruz (21). Acacia pennatula Cham. \& Schldl. (Fabaceae) is a small and spiny deciduous tree $(8$ to $10 \mathrm{~m}$ tall) distributed from northern Mexico to Central America between 100 and $900 \mathrm{~m}$ above sea level. A characteristic species of extensive areas of subtropical dry scrub, in central Veracruz it is commonly found in pastures and disturbed cloud forest areas. Liquidambar styraciflua var. mexicana (= macrophylla Oested., Altingiaceae) is a deciduous tree naturally distributed from Connecticut, United States to central Nicaragua. In Mexico, it is distributed along the Sierra Madre Oriental from Nuevo León and Tamaulipas to the Sierra Madre del Sur in Oaxaca, north of Chiapas, and in the Pacific slope in the Sierra del Soconusco, Chiapas. It is a pioneer, heliophilous, and invasive tree species in early stages of succession between 400 and 1,800 m of elevation. Platanus mexicana Moric. (Platanaceae) is a deciduous tree (15 to $25 \mathrm{~m}$ tall) distributed from eastern Mexico to Guatemala. It is most commonly found in canyons and along streams and rivers at altitudes ranging from 160 to 2,400 m above sea level. Quercus germana Cham. \& Schldl. (Fagaceae) is an evergreen species endemic to the cloud forest of eastern Mexico from Tamaulipas to Oaxaca. It is reported as vulnerable by the IUCN mainly because coffee plantations have replaced the cloud forest. These host species flush their leaves almost entirely between November and February (the period of fruit ripening of mistletoe), except $Q$. germana, which flushes leaves all year round (23). Although we focused on host tree species of Psittacanthus schiedeanus with higher prevalence, no further information is available on host damage by these mistletoe species.

The vector. Grey silky-flycatchers (Ptilogonys cinereus Swainson: Ptilogonatidae) are distributed from northern Mexico to Guatemala between 1,000 and 3,500 m of elevation (11). In Mexico, they inhabit pine-evergreen forest, cloud forest, and disturbed areas. They usually arrive at single infected trees in pairs or small flocks of three to six individuals and commonly perch on the upper branches. Grey silky-flycatchers consume a lot of fruit of Psittacanthus schiedeanus. They pluck and swallow mistletoe fruit whole from nearby mistletoe plants, defecating complete seed on the adjacent host branches, and, because of this, they are considered one of the major seed dispersers of this mistletoe (21). The digestive physiology of this species is unknown but we know that the viability and the rate of germination of mistletoe seed are not affected by the transit time ( 20 to $30 \mathrm{~min})$ in their digestive tract $(18,21,23,38)$.

Experimental design. To determine the effects of mistletoe host provenance and host fate on seed germination, seedling establishment, and seedling survival, we conducted a cross-inoculation experiment in the P. schiedeanus fruiting season of 2005. Mistletoe seed from four host species (host provenances) $-A$. pennatula, $L$. styraciflua, Platanus mexicana, and $Q$. germana-were placed on branches of other trees of the same four species (host fate) in a full 
factorial design. The experiment included fruit that had their exocarp and pulp manually removed and fruit with seed consumed and defecated by Ptilogonys cinereus.

Fruit collection. We collected mature mistletoe fruit of plants growing on the four selected host species (A. pennatula, L. styraciflua, Platanus mexicana, and $Q$. germana; Fig. 1). All fruit were collected from different mistletoe plants located on trees 10 $\mathrm{km}$ north of our seed inoculation site and randomly selected host trees of unknown genetic relatedness.

Fruit treatment. One group of fruit had their exocarp and pulp manually removed, were then placed on branches of unparasitized host trees (Fig. 1). Another group of fruit were given to 11 Ptilogonys cinereus birds captured in the same study area during November 2005. Birds were maintained in the laboratory in separate cages (50 by 30 by $50 \mathrm{~cm}$ ) at ambient temperature $\left(25 \pm 2^{\circ} \mathrm{C}\right)$ with a photoperiod of $12 \mathrm{~h}$ of darkness and $12 \mathrm{~h}$ of light, and fed with small pieces of banana and water ad libitum. We ensured that the birds were accustomed to eating the artificial diet, and did so readily (38). Birds remained on the maintenance diet during the experiments. Mistletoe fruit were provided to all birds during the acclimatization time to ensure their consumption during experimental trials. Birds were maintained in captivity for 1 month and the experiment was conducted after the second week of captivity. After the experiments were done, birds were released.

Twelve hours before experimental trials, birds were fasted to ensure that their digestive tracts were empty. Each bird was fed 10 ripe mistletoe fruits from the same host at start of a trial. We observed birds continuously through one-way mirrors for the next $3 \mathrm{~h}$ until seed disposal, after which time we removed sheets of newspaper from the bottom of the cage. The 11 birds were fed 30 to 40 fruits per 3-h trial. After the fruit were consumed and the seed defecated, seed were collected from the excreta and placed on the branches of the selected trees the same day. This protocol was repeated every other day through 30 consecutive days using fresh mistletoe fruit from the four host tree species. As needed, fruit were collected the day before each trial and from the same site to avoid any seed age or site effect on germination. Birds did not swallow unripe fruit or fruit kept in a freezer (38). Therefore, we chose to give them only fleshy ripe fruit collected the day before the feeding trials to minimize possible confounding effects of the type of food ingested along with the fruit (or seed) on gut retention time and germination.

Seed inoculation. We applied gut-passed and manually extracted seed from a given host source $(n=25$ seeds per treatment per host of origin) on each of five different branches of five trees per host species. Because seed were not stored and all were inoculated right after disposal by birds or manual depulping, we assumed that testing for seed vigor was not necessary before inoculation. In order to avoid the possibility that prior infection by mistletoe induces changes in the host tree that might reduce the chance of subsequent infection, none of the host trees was infected by mistletoe prior to our inoculations (Fig. 1). Seed were adhered to the branch by carefully sticking them in place with their natural viscin. Diameter of branches used for the inoculations ranged from 5 and $10 \mathrm{~mm}$ wide and 100 to $150 \mathrm{~cm}$ in length. Each branch had eight mistletoe seed randomly placed, one gut-passed seed from each of the four hosts
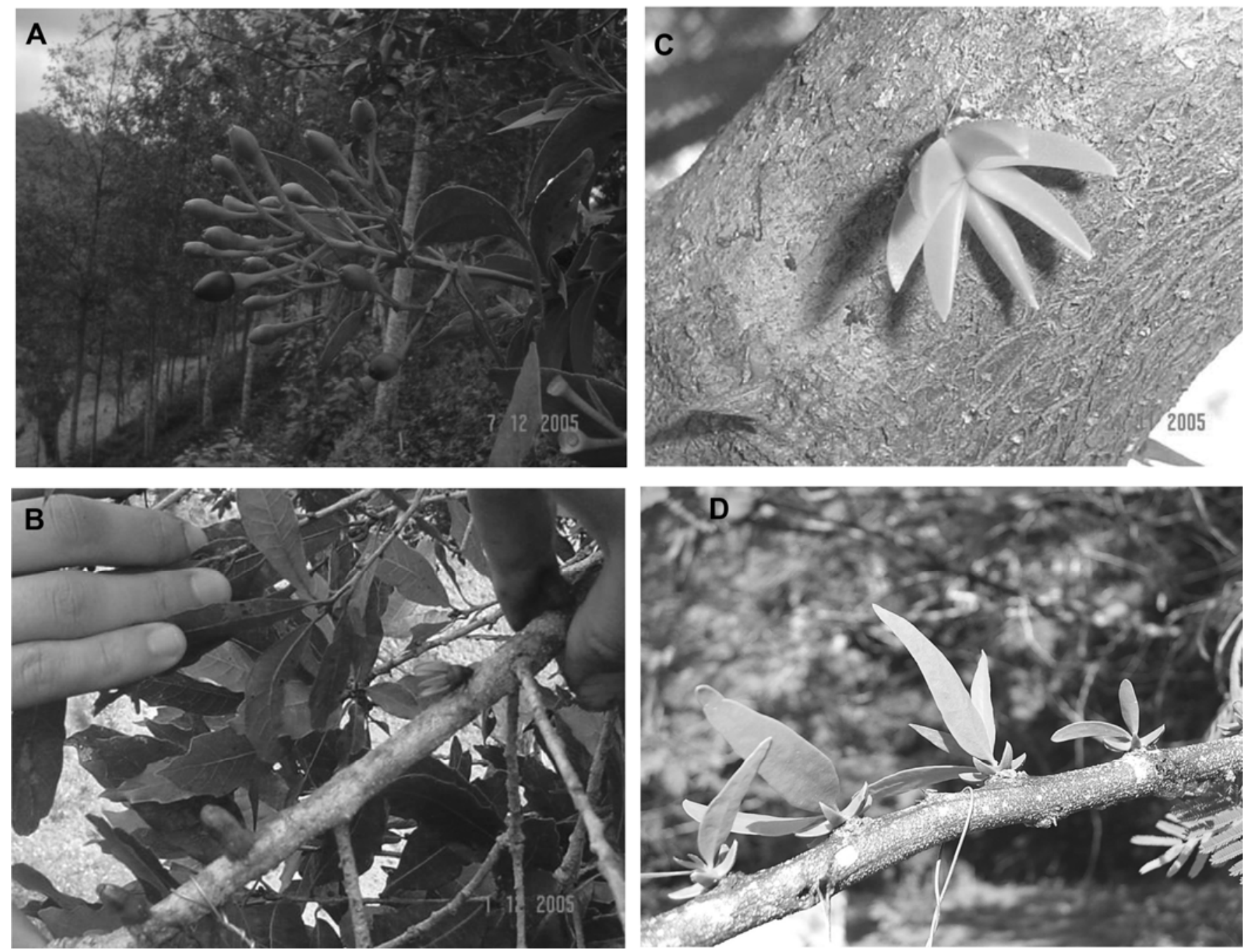

Fig. 1. Seed inoculation experiment of Psittacanthus schiedeanus seed. A, Ripe and unripe mistletoe fruit. B, Host branch inoculated with manually extracted and gut-passed mistletoe seed from mistletoe plants on four host species. C, Germinated mistletoe seed. D, Mistletoe seedlings. 
and one manually extracted from each of the four hosts. After inoculation, seed fate was monitored daily for 4 weeks until germination and once a month for one-and-a-half years (18 months) until seedling establishment and seedling survival (Fig. 1). On each census, individual seed were categorized as germinated if the hypocotyl had emerged, established if the first set of small leaves appeared, or dead. The occurrence of germination and seedling establishment and time elapsed since inoculation for each seed was assessed.

An experimental design for testing the effects of gut passage on seed germination should include the following treatments (48): (i) manually extracted seed, with exocarp or pulp manually extracted from fruit and placed on a germination substrate; (ii) gut-passed seed; consisting of those consumed by birds (defecated, regurgitated, or both) and then placed on a germination substrate; and (iii) fruit with seed placed directly on the germination substrate. However, seed from intact Psittacanthus schiedeanus mistletoe fruit do not germinate, and pulp removal is needed for seed adhesion with the natural viscin onto a host tree branch $(18,38)$. Therefore, we simplified our experimental design and only included the treatments of manually extracted seed and gut-passed seed.

Statistical analysis. We used three-way analysis of variance (ANOVA) to evaluate the effects of host provenance, host fate, and fruit treatment (manually extracted seed and gut-passed seed) on seed germination. In the model, host provenance, fruit treatment, host fate, and their interactions were fixed main effects and the number of days from inoculation until germination was the dependent variable. Data were $\log (x+1)$ transformed. Differences between groups were compared with post hoc pairwise tests using SuperANOVA (Abacus Concepts, Inc.).

Evaluation of seed germination, seedling establishment, and seedling survival were analyzed as binary variables $(0=$ did not occur and $1=$ did occur) using a nested general linear model (GLM). The response variables were analyzed with a binomial error and a logit link function using the computer program R (40). The GLM nested models included the factors host provenance ( $A$. pennatula, L. styraciflua, Platanus mexicana, and $Q$. germana) as the main level and fruit treatment (manually extracted seed and gut-passed seed), and host fate (A. pennatula, L. styraciflua, $P$. mexicana, and $Q$. germana) were nested within the main level. Best models were chosen using the backward elimination of nonsignificant terms, starting with three-way interactions whenever these were included in the full model. The significance of a particular term adjusted for the effects of other terms was based on the change in deviance between the full and simplified models, distributed as $\chi^{2}$ with degrees of freedom equal to the difference in the degrees of freedom between the models with and without the term in question. Paired comparisons were also carried out with the package gmodels of $\mathrm{R}$ for the variables and their interactions.

\section{Results}

Germination time. The three-way ANOVA showed that time taken from mistletoe seed inoculation to germination of seed was affected significantly by host provenance $\left(F_{3,752}=6.46, P=\right.$ $0.003)$, host fate $\left(F_{3,752}=7.86, P<0.0001\right)$, and fruit treatment $\left(F_{1,752}=10.49, P=0.0013\right)$. The seed from plants on A. pennatula germinated faster (7.2 \pm 0.4 days) compared with those of plants on $L$. styraciflua ( $7.5 \pm 0.3$ days), Q. germana ( $8.2 \pm 0.5$ days), and $P$. mexicana ( $8.6 \pm 0.5$ days). Seed that were inoculated on $P$. mexicana and $A$. pennatula germinated faster ( $P$. mexicana, $6.8 \pm 0.3$ days; A. pennatula, $7.7 \pm 0.5$ days) than those that were deposited on branches of $Q$. germana ( $8.3 \pm 0.4$ days) and L. styraciflua (8.7 \pm 0.5 days). For fruit treatment, manually extracted seed germinated faster (7.4 \pm 0.3 days) compared with gut-passed seed $(8.4 \pm$ 0.3 days). The two- and three-way interactions were not significant $(P>0.05)$, except the host provenance-host fate interaction $\left(F_{9,752}\right.$ $=3.35, P<0.0005$; Fig. 2).

Seed germination. Of 800 manually inoculated seed (200 on each host species), $762(95.2 \%)$ did germinate after 18 days of inoculation (Table 1). Manually extracted seed had higher germination percentages compared with gut-passed seed (Table 1), although this difference was not statistically significant. When analyzed within a GLM framework, the simplified model (see Methods for details on variables included in the full model) suggests that the effects of host provenance on the occurrence of germination varied among host species. After simplification, the GLM model only included host provenance (Table 2). The significant host provenance effect was largely due to higher germination of seed from plants on L. styraciflua and A. pennatula (197 mistletoe seed germinated on both species, $n=200$ inoculated seed per host species) than seed from plants on $Q$. germana and $P$. mexicana (188 and 180 germinated seed, respectively; $n=200$ inoculated seed per host species; Table 2).

Seedling establishment. More than $95 \%$ of germinated seed (738 of 762) survived to establishment. Out of those seedlings that established, manually extracted seed were more likely to establish (99\%) than gut-passed seed $(94.7 \%$; Table 1). Again, host provenance had a significant effect on seedling establishment. Host provenance and the host provenance-fruit treatment interaction were significant in the simplified model (Table 2). The simplified model suggests that seedling establishment was less likely when seed were gut passed. The significant host provenance-fruit treatment interaction was largely due to a lower seedling establishment of gut-passed seed from P. mexicana to P. mexicana, A. pennatula, Q. germana, and L. styraciflua (Table 2).

Seedling survival. After 18 months, more than $91 \%$ of established seedlings died (671 of 738). The simplified model suggests that variation in seedling survival of $P$. schiedeanus was explained by the host provenance-host fate interaction (Table 2). In general, seedling survival was more likely when seed from $L$. styraciflua and $P$. mexicana were inoculated on L. styraciflua and P. mexicana, respectively (Fig. 3). Survival of mistletoe seedlings from $L$. styraciflua and $P$. mexicana was more than $15 \%$ in all host species, except for those of L. styraciflua on P. mexicana $(<7 \%)$. Note that mistletoe seed from $Q$. germana were less likely to survive when deposited on $Q$. germana compared with seedling survival on the other host trees. When mistletoe seed from $A$. pennatula, $P$. mexicana, and $L$. styraciflua were deposited on $Q$. germana, low to no survival of mistletoe seedlings was observed. These results suggest the existence of a mechanism of resistance to infection that precludes the establishment of $P$. schiedeanus on Q. germana (Fig. 3).

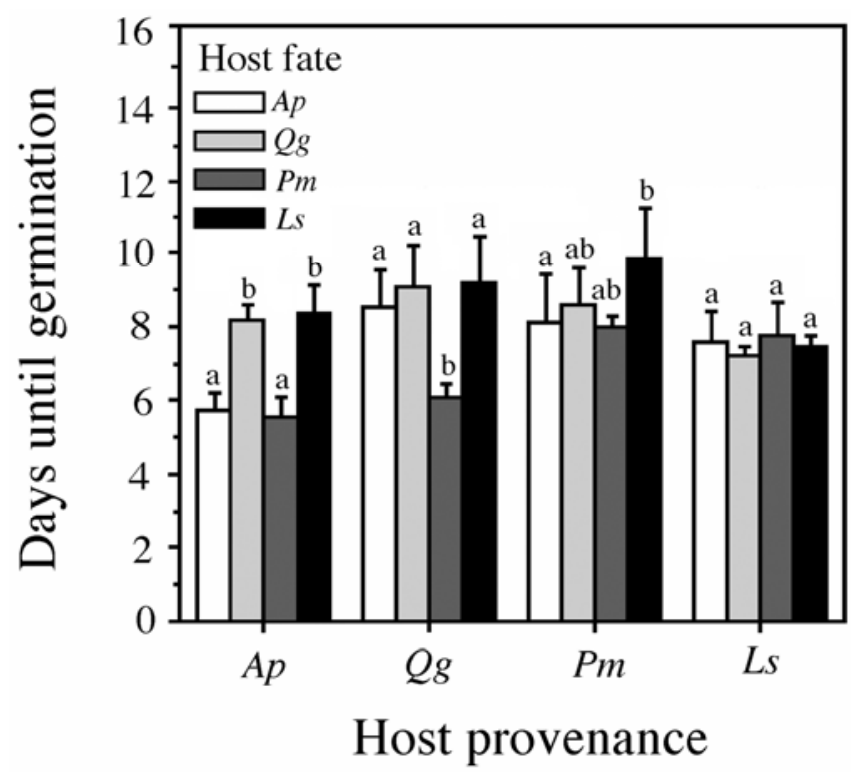

Fig. 2. Effects of host provenance and host fate on seed germination (time elapsed since inoculation) for Psittacanthus schiedeanus. $A p=$ Acacia pennatula, $L s=$ Liquidambar styraciflua, $P m=$ Platanus mexicana, and $\mathrm{Qg}=$ Quercus germana. 


\section{Discussion}

Our cross-infection experiments partially support the hypothesis that mistletoe establishment is affected by the interaction between the origin of the fruit consumed (host provenance) and the infection susceptibility of the host tree species where seed were deposited (host fate) but the effects of bird gut processing on seedling survival were not significant. At central Veracruz, these crossinfection experiments gave no evidence that Psittacanthus schiedeanus consisted of several host-specific races, one specializing on A. pennatula and the others specializing on L. styraciflua, Platanus mexicana, or Q. germana. If this were the case, then, on a given host species, one would expect the seed collected from Psittacanthus schiedeanus growing on that host species to establish and survive better than seed from $P$. schiedeanus growing on the other host species (37). This was partially supported by the results of the cross-infection experiments. On both L. styraciflua and Platanus mexicana, the seed from those host species had a higher survival success than the seed from the other two host species. On average, seed inoculated on L. styraciflua and $P$. mexicana survived better than seed inoculated on A. pennatula and $Q$. germana, but seedling survival was more likely when Psittacanthus schiedeanus seed collected from L. styraciflua and Platanus mexicana were inoculated on L. styraciflua and P. mexicana, respectively. There- fore, our results suggest that patterns of prevalence and infection intensity of Psittacanthus schiedeanus mistletoe $(21,23)$ may be explained by the significant host provenance-host fate interaction and, ultimately, by mistletoe-host compatibility mechanisms.

The existence of host-specific relationships has been suggested for a number of mistletoe species using cross-dispersal experiments $(6,18,27,37)$ and isozyme variation (9), which showed the existence of host-specific races. May (27) and Clay et al. (6) established the existence of host-specific races for Phoradendron tormentosum (Viscaceae) by using cross-inoculation experiments. They observed that the development of haustorial disks was significantly higher when the host provenance and the host fate was the same than when provenance and fate of hosts were different. Glazner et al. (9) investigated isozyme and morphological variation within and between populations of Phoradendron californicum growing on A. greggii and Prosopis grandulosa in southern California, and found evidence of race specialization in the mistletoe. Overton (37) also showed the existence of host-specific types of $P$. californicum, each of which infects Acacia and Prosopis trees. He showed that $P$. californicum was forming two types (or races) of mistletoe specializing in different hosts in northern Baja California. In the same area, one type successfully parasitized Prosopis articulata trees and the other established on A. greggii and Cercidium microphyllum. These differences in mistle-

Table 1. Germination, seedling establishment, and seedling survival of Psittacanthus schiedeanus by host provenance, fruit treatment, and host fate ${ }^{\mathrm{a}}$

\begin{tabular}{|c|c|c|c|c|c|c|c|c|}
\hline \multirow[b]{2}{*}{ Host provenance, host fate } & \multicolumn{4}{|c|}{ Manually extracted } & \multicolumn{4}{|c|}{ Gut-passed } \\
\hline & $n$ & $\mathbf{G}$ & $\mathbf{E}$ & $\mathbf{S}$ & $n$ & $\mathbf{G}$ & $\mathbf{E}$ & $\mathbf{S}$ \\
\hline \multicolumn{9}{|l|}{ Acacia pennatula } \\
\hline A. pennatula & 25 & 100 & 100 & 12 & 25 & 96 & 100 & 12 \\
\hline Liquidambar styraciflua & 25 & 100 & 100 & 32 & 25 & 92 & 100 & 20 \\
\hline Platanus mexicana & 25 & 100 & 100 & 40 & 25 & 100 & 96 & 8 \\
\hline Quercus germana & 25 & 100 & 100 & 0 & 25 & 100 & 92 & 0 \\
\hline \multicolumn{9}{|l|}{ L. styraciflua } \\
\hline A. pennatula & 25 & 100 & 100 & 12 & 25 & 96 & 100 & 8 \\
\hline L. styraciflua & 25 & 100 & 100 & 32 & 25 & 100 & 96 & 16 \\
\hline P. mexicana & 25 & 96 & 100 & 28 & 25 & 100 & 96 & 16 \\
\hline Q. germana & 25 & 100 & 96 & 4 & 25 & 96 & 100 & 0 \\
\hline \multicolumn{9}{|l|}{ P. mexicana } \\
\hline A. pennatula & 25 & 96 & 100 & 16 & 25 & 72 & 80 & 4 \\
\hline L. styraciflua & 25 & 88 & 96 & 4 & 25 & 88 & 88 & 12 \\
\hline P. mexicana & 25 & 100 & 100 & 28 & 25 & 96 & 88 & 20 \\
\hline Q. germana & 25 & 92 & 92 & 0 & 25 & 88 & 96 & 0 \\
\hline \multicolumn{9}{|l|}{ Q. germana } \\
\hline A. pennatula & 25 & 96 & 100 & 12 & 25 & 96 & 100 & 12 \\
\hline L. styraciflua & 25 & 92 & 100 & 12 & 25 & 92 & 100 & 20 \\
\hline P. mexicana & 25 & 100 & 100 & 24 & 25 & 92 & 88 & 8 \\
\hline Q. germana & 25 & 92 & 100 & 4 & 25 & 92 & 96 & 0 \\
\hline
\end{tabular}

${ }^{\mathrm{a}} \mathrm{G}=$ germination (\%), $\mathrm{E}=$ establishment (\%), and $\mathrm{S}=\operatorname{survival}(\%)$.

Table 2. Effects of host provenance (Acacia pennatula, Liquidambar styraciflua, Platanus mexicana, and Quercus germana) fruit treatment (manual extracted seed and gut-passed seed) and host fate (A. pennatula, L. styraciflua, P. mexicana, and Q. germana) on (i) seed germination, (ii) seedling establishment, and (iii) seedling survival for Psittacanthus schiedeanus using generalized linear models with a nested design ${ }^{\mathrm{a}}$

\begin{tabular}{|c|c|c|c|c|c|}
\hline Model & df & Deviance & Residual df & Residual deviance & $P\left(\chi^{2}\right)^{b}$ \\
\hline \multicolumn{6}{|l|}{ Seed germination } \\
\hline Null & $\ldots$ & $\ldots$ & 799 & 305.74 & \\
\hline Host provenance & 3 & 22.613 & 796 & 283.13 & $0.0000486 * * *$ \\
\hline \multicolumn{6}{|l|}{ Seedling establishment } \\
\hline Null & $\ldots$ & $\ldots$ & 799 & 222.5 & \\
\hline Host provenance & 3 & 14.422 & 796 & 208.07 & $0.002384 * *$ \\
\hline Host provenance-fruit treatment & 4 & 16.397 & 792 & 191.68 & $0.002531 * *$ \\
\hline \multicolumn{6}{|l|}{ Seedling survival } \\
\hline Null & $\ldots$ & $\ldots$ & 799 & 618.22 & \\
\hline Host provenance & 3 & 3.02 & 796 & 615.2 & 0.38858 \\
\hline Host provenance-fruit treatment & 4 & 8.943 & 792 & 606.26 & 0.06253 \\
\hline Host provenance-host fate & 12 & 66.767 & 780 & 539.49 & $1.28 \mathrm{E}-09 * * *$ \\
\hline
\end{tabular}

a Seed germination (germinated or not germinated), seedling establishment (established or not established), and seedling survival (alive or dead) were analyzed as a binary response variable with binomial error and logit link function. The residual deviance was calculated with the simplified model. Only results of the simplified models are shown.

b Asterisks: ***, **, and * indicate $P<0.0001,0.01$, and 0.1 , respectively. 
toe seed establishment occurred when seed collected from Phoradendron plants on Prosopis trees established and survived better when seed were placed on Prosopis trees. Furthermore, he observed that the blooming time between these two mistletoe types differed, in which plants growing on Prosopis trees flowered significantly later than those growing on any other host, implying a partial reproductive isolation between these two types of mistletoe. The formation of host races on different host provenances (genotypes) of the same host species, Nothofagus solandri, or the susceptibility of different host provenances to mistletoe infection, was not detected on New Zealand mistletoe Peraxilla tetrapelata and Alepis flavida (34).

For cross-inoculation experiments with Psittacanthus spp., Overton (36) found no evidence for host-specific races of Psittacanthus (= Phrygilanthus) sonorae growing on Bursera microphylla and $B$. hindsiana in Baja California, Mexico. In $P$. calyculatus, Lara and collaborators (18) found a consistent effect of host tree species on the germination and establishment success of seed inoculated on a specific tree in Tlaxcala, Mexico. They showed that host trees within an area (Prunus serotina and Crataegus pubescens) supporting a mistletoe seed flow by their fruit consumer can differ in susceptibility to infection than host tree species away from that area (Salix bonplandiana), where mistletoe are not commonly deposited. Here, our cross-seed-inoculation experiments showed that success of Psittacanthus schiedeanus on seedling survival depends on the interaction between host provenance and host fate, where mistletoe seed collected from $L$. styraciflua and Platanus mexicana are more likely to survive when they were inoculated on conspecific host trees compared with those inoculated on other host provenances. Nonetheless, it may be helpful if future studies of host provenance effects on mistletoe establishment consider that different hosts grow under different conditions and that these abiotic factors might explain the observed differences in seedling survival.

Norton and Carpenter (30) suggested that specialization between mistletoe and their hosts is determined mainly by the relative abundance of hosts. Although previous studies have suggested that the degree of specialization and patterns of $P$. schiedeanus infestation can be explained, in part, by the relative host abundance $(21,23,24)$, the role of the relative host abundance in determining host specificity needs to be further evaluated by examining the abundance of host species along the geographic distribution of Psittacanthus schiedeanus, where different races of mistletoe might occur (30). If differences in host provenance susceptibility to infection could lead to the formation of mistletoe races on particular host provenances and, hence, adaptation of mistletoe to local host provenances occurs, then mistletoe seedling survival would be higher on the same hosts from which the mistletoe seed were collected. Interestingly, the interaction between host provenance and host fate had a significant and positive effect on seedling survival. These results suggest the existence of a morphological, chemical, physiological, or a phenological mechanism genetically determined for recognition of different host species. Host specificity at the stage of haustorium formation has been demonstrated in reciprocal transplant experiments that found haustorium formation to be greater on source or parental host species (provenance) $(35,44)$, indicating that there is tight mistletoe-source coupling $(6,8,9,35)$. Mistletoe-host compatibility in Viscum rotundifolium was demonstrated (35), in which the mistletoe seed experimentally inoculated on fleshy cut branches formed more cotyledons and hypocotyls attachments on Ehretia rigida and Ziziphus mucronata than seed deposited on co-occurring potential host species (four Acacia spp., Tarchonanthus camphorates, and Searsia lancea). Alternatively, host specificity in a local host and the differential success of individual mistletoe in a population in the use of their hosts may be genetically determined, and this would allow the formation of different race of parasites that may seem morphologically similar but differ in the use of their hosts. This hypothesis is consistent with our results, where the highest proportion of surviving seedlings on L. styraciflua and Platanus mexicana occurred when they had the same host provenance. This apparent host specificity could be generating mistletoe races that are specializing in a specific local host, thus generating adapted genotypes that might have an impact at the population level of parasitic plants. Other studies support the existence of a specific host for other species of mistletoe in cross-inoculation experiments $(6,18,37)$, results that strengthen this interaction results based on molecular analysis $(12,20)$. However, the ability of Psittacanthus mistletoe to recognize its compatible hosts seems to appear after seed germination and may be caused by nutrient, chemical, or phenological differences among host species that subsequently direct local host specificity, and preferences for such cues must be inherited and passed on to the next generation for host specificity to be heritable. The low survival of mistletoe seed on $Q$. germana suggests the existence of a mechanism of resistance to infection that precludes the establishment of Psittacanthus schiedeanus on this host species, where fewer seed from plants on $Q$. germana survived when they were deposited on $Q$. germana than those deposited on other host species (Fig. 3). In fact, mistletoe seedlings were not at all successful on $Q$. germana, mainly because seedlings from Acacia pennatula and Platanus mexicana did not show any survival on $Q$. germana. A crucial next step in this cross-inoculation experiment would be to investigate the role of bark traits and physiological conditions of hosts precluding the penetration of the mistletoe haustorium and growth of mistletoe on host tissues, and how herbivory and environmental factors such as humidity, temperature, and light levels on deciduous (A. pennatula, L. styraciflua, and P. mexicana) and evergreen ( $Q$. germana) host canopies influence seedling survival and the parasite-host relationship.

In the case of our in situ seed inoculation experiment of Psittacanthus schiedeanus, the effects of fruit treatment (manually extracted versus gut-passed seed) were not significant on seed germination, and the only factor having a significant effect on seed germination was host provenance. Results of seedling establishment were similar to those of seed germination, where mistletoe seed inoculated on Platanus mexicana were more likely to germinate and seedlings to establish than seed inoculated on the other hosts (Table 2). The significant host provenance-fruit treatment interaction of our simplified model was largely due to a lower seedling establishment of gut-passed seed from $P$. mexicana to $P$. mexicana, A. pennatula, Q. germana, and L. styraciflua (Table 2). Recent studies evaluating the passage of mistletoe seed through the digestive tract of bird seed dispersers have shown mainly that manually extracted mistletoe seed germinate in almost any situation $(35,44,46)$, and an improvement in germination was observed when the seed have passed through the digestive tract of birds $(18,35,45,50)$. There is evidence that defecated seed can germinate

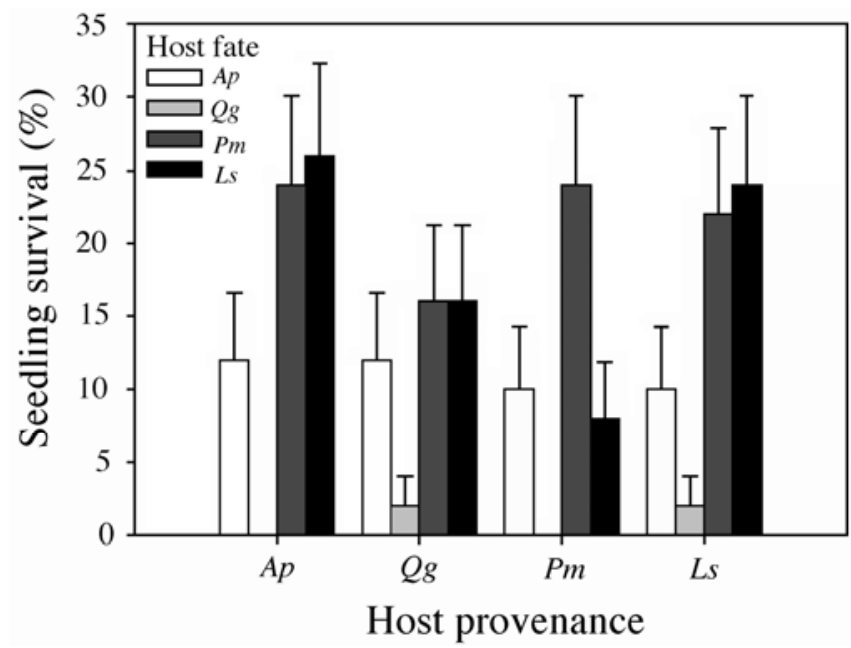

Fig. 3. Effects of host provenance and host fate on seedling survival (18 months since inoculation) for Psittacanthus schiedeanus. $A p=$ Acacia pennatula, $L s=$ Liquidambar styraciflua, $P m=$ Platanus mexicana, and $\mathrm{Qg}=$ Quercus germana. 
at a higher rate and shorter time than seed that were regurgitated or depulped manually $(18,50)$. In the case of Psittacanthus schiedeanus, we have shown that seed that were regurgitated by Ptilogonys cinereus and Bombycilla cedrorum did not germinate under controlled conditions, in contrast to control (manually extracted) or gut-passed (defecated) seed, which germinated and did so faster than the former (38). Under natural conditions, we showed that bird-gut-processed seed had germination and seedling establishment rates similar to that of seed from fruit with the pulp manually removed. These results suggest that germination of Psittacanthus schiedeanus seed is not enhanced by the chemical and physical scarification by digestive enzymes or by washing away of the seminal cover, allowing relaxation of dormancy due to water incorporation, exchange of gases, or release of inhibitors in the testa teguments (48). Given that mistletoe seed are not known to display any form of dormancy, germinate as soon as they are released from the exocarp $(17,53)$, do not have a seed coat (15), and pass through the digestive tract of Ptilogonys cinereus without improvement in seed germination, our data suggest, instead, that scarification and seed dormancy seem unlikely to have any effect on the germination, and passing through the digestive tract of $P$. cinereus is the only mechanism for the seed to arrive at host branches and adhere.

In summary, our cross-seed-inoculation experiments showed that success for survival of Psittacanthus schiedeanus seedlings depends on the interaction between host provenance and host fate. Interestingly, our results suggest that mistletoe seed collected from L. styraciflua and Platanus mexicana are more likely to survive when they were inoculated on conspecific host trees compared with those inoculated on other host provenances. This suggests the potential for local host adaptation, and the underlying causes of this result warrant further investigation.

\section{Acknowledgments}

Funding was provided by a research grant (2005-01) from the fellowship graduate program of the Instituto de Ecología, A.C. and a doctoral scholarship (171228) granted by the Consejo Nacional de Ciencia y Tecnología (CONACyTMéxico) to M. M. Ramírez, and research funds (902-12-563) from the Departamento de Biología Evolutiva, Instituto de Ecología, A.C. to J. F. Ornelas. This work constitutes partial fulfillment of M. M. Ramírez's doctorate in Ecología y Manejo de Recursos Naturales at the Instituto de Ecología, A.C. We thank P. Ibarra, I. Ruán, G. Hernández, T. Velazquez, and J. P. Esparza for help in fieldwork; C. Lara and R. Guevara for statistical advice and data analysis; and T. Valverde, C. Montaña, G. Amico, and one anonymous reviewer for useful comments on previous versions of this manuscript.

\section{Literature Cited}

1. Arruda, R., Carvalho, L. N., and Del-Claro, K. 2006. Host specificity of a Brazilian mistletoe, Struthanthus aff. polyanthus (Loranthaceae), in cerrado tropical savanna. Flora 201:127-134.

2. Aukema, J. E. 2004. Distribution and dispersal of desert mistletoe is scaledepend, hierarchically nested. Ecography 27:137-144.

3. Aukema, J., and Martínez del Rio, C. 2002. Where does a fruit-eating bird deposit mistletoe seeds? Seed deposition patterns and experiment. Ecology 83:3489-3496.

4. Aukema, J. E., and Martínez del Rio, C. 2004. Where does a fruit-eating bird deposit mistletoe seeds? Seed deposition patterns and an experiment. Ecology 83:3489-3496.

5. Cházaro, M., and Oliva, R. 1988. Loranthaceae del centro de Veracruz y zona limítrofe de Puebla, IV. Cact. Suculentas Mex. 33:42-48.

6. Clay, K., Demet, D., and Rejmanek, M. 1985. Experimental evidence for host races in mistletoe Phoradendron tomentosum (Viscaceae). Am. J. Bot. 72:1225-1231.

7. Davidar, P. 1983. Birds and Neotropical mistletoes: Effects on seedling recruitment. Oecologia 60:271-273.

8. Ferreira M. R., Parentoni, R., and Yamamoto, K. 1992. Host specificity and seed dispersal of Psittacanthus robustus (Loranthaceae) in south-east Brazil. J. Trop. Ecol. 8:307-314.

9. Glazner, J. T., Devlin, B., and Ellstrand, N. 1988. Biochemical and morphological evidence for host race evolution in desert mistletoe, Phoradendron californicum (Viscaceae). Plant Syst. Evol. 161:13-21.

10. Hoffmann, A. J., Fuentes, E. R. Cortés, I. Liberona, F., and Costa, V. 1986. Tristerix tetrandus (Loranthaceae) and its host-plants in the Chilean matorral: Patterns and mechanisms. Oecologia 6:202-206.

11. Howell, S., and Webb, S. 1999. The Birds of México and Northern Central America. Oxford University Press, Oxford.

12. Jerome, C. A., and Ford, B. A. 2002. Comparative population structure and genetic diversity of Arceuthobium americanum (Viscaceae) and its Pinus host species: Insight into host-parasite evolution in parasitic angiosperms. Mol. Ecol. 11:407-420.

13. Kuijt, J. 1969. The Biology of Parasitic Flowering Plants. University of California Press, Berkeley.

14. Kuijt, J. 1987. Novelties in Mesoamerican mistletoes (Loranthaceae and Viscaceae). Ann. Miss. Bot. Gard. 74:511-532.

15. Kuijt, J. 2009. Monograph of Psittacanthus (Loranthaceae). Systematic Botany Monographs, Vol. 86. American Society of Plant Taxonomists, Ann Harbor, MI.

16. Ladley, J. J., and Kelly, D. 1996. Dispersal, germination and survival of New Zealand mistletoes (Loranthaceae): Dependence on birds. N. Z. J. Ecol. 20:69-79.

17. Lamont, B. 1983. Germination of mistletoes. Pages 129-143 in: The Biology of Mistletoes. M. Calder and V. Bernhardt, eds.. Academic Press, Sydney, Australia.

18. Lara C., Pérez, G., and Ornelas, J. F. 2009. Provenance, guts, and fate: Field and experimental evidence in a host-mistletoe-bird system. Ecoscience 16:399-407.

19. Lichter, J. M., and Berry, A. M. 1991. Establishment of the mistletoe Phoradendron macrophyllum: Phenology of early stages and host compatibility studies. Bot. Gaz. 152:448-475.

20. Linhart, Y. B., Malville Ellwood, L., Karron, J. D., and Gehring, J. L. 2003. Genetic differentiation in the dwarf mistletoes Arceuthobium vaginatum and Arceuthobium americanum on their principal and secondary hosts. Int. J. Plant Sci. 164:61-69.

21. López de Buen, L., and Ornelas, J. F. 1999. Frugivorous birds, host selection and the mistletoe Psittacanthus schiedeanus, in central Veracruz, Mexico. J. Trop. Ecol. 15:329-340.

22. López de Buen, L., and Ornelas, J. F. 2001. Seed dispersal on the mistletoe Psittacanthus schiedeanus by birds in central Veracruz, Mexico. Biotropica 33:487-494.

23. López de Buen, L., and Ornelas, J. F. 2002. Host compatibility of the cloud forest mistletoe Psittacanthus schiedeanus (Loranthaceae) in central Veracruz, Mexico. Am. J. Bot. 89:95-102.

24. López de Buen, L., Ornelas, J. F., and García-Franco, J. G. 2002. Mistletoe infection of trees located at fragmented forest edges in the cloud forest of central Veracruz, Mexico. For. Ecol. Manage. 164:293-302.

25. Martínez del Rio, C., Silva, A., Medel, R., and Hourdequin, M. 1996. Seed dispersers as disease vectors: Bird transmission of mistletoe seed to plant hosts. Ecology 77:912-921.

26. Mathiasen, R. L., Nickrent, D. L., Shaw, D. C., and Watson, D. M. 2008 Mistletoes: Pathology, systematics, ecology, and management. Plant Dis. 92:988-1006.

27. May, D. S. 1971. The role of population differentiation in experimental infection of Prosopis by Phoradendron. Am. J. Bot. 58:921-931.

28. Monteiro, R. E., Martins, R. P., and Yamamoto, K. 1992. Host specificity and seed dispersal of Psittacanthus robustus (Loranthaceae) in southeast Brazil. J. Trop. Ecol. 8:307-314

29. Murphy, S. R., Reid, N. Yan, Z., and Venables, W. N. 1993. Differential passage time of mistletoe fruit through the gut of honeyeaters and flowerpeckers: Effect on seedling establishment. Oecologia 93:171-176.

30. Norton, D., and Carpenter, M. A. 1998. Mistletoes as parasites: Host specificity and speciation. Tree 13:101-105.

31. Norton, D. A., and de Lange, P. J. 1999. Host specificity in parasitic mistletoes (Loranthaceae) in New Zealand. Funct. Ecol. 13:552-559.

32. Norton, D. A., and Ladley, J. 1998. Establishment and early growth of Alepis flavida in relation to Nothofagus solandri branch size. N. Z. J. Bot. 36:213-217.

33. Norton, D. A., Ladley, J., and Owen, H. J. 1997. Distribution and population structure of the loranthaceous mistletoes Alepis flavida, Paraxilla colensoi and Paraxilla tetrapetala within two New Zealand Nothofagus forests. N. Z. J. Bot. 35:323-336.

34. Norton, D. A., Ladley, J., and Sparrow, A. D. 2002. Host provenance effects on germination and establishment of two New Zealand mistletoes (Loranthaceae). Funct. Ecol. 16:657-663.

35. Okubamichael, D. Y., Griffiths, M. E., and Ward, D. 2011. Host specificity, nutrient and water dynamics of the mistletoe Viscum rotundifolium and its potential host species in the Kalahari of South Africa. J. Arid Environ. 75:898-902.

36. Overton, J. M. 1994. Dispersal and infection of mistletoe metapopulations. J. Ecol. 82:711-723.

37. Overton, J. M. 1997. Host specialization and partial reproductive isolation in desert mistletoe (Phoradendron californicum). Southwest. Nat. 42:201209.

38. Ramírez, M. M., and Ornelas, J. F. 2009. Germination of Psittacanthus schiedeanus (mistletoe) seeds after passage through the gut of Cedar Waxwings and Grey Silky-flycatchers. J. Torrey Bot. Soc. 136:322-331.

39. Ramírez, M. M., and Ornelas, J. F. 2010. Pollination and nectar production of Psittacanthus schiedeanus (Loranthaceae) in Central, Veracruz, Mexico. Bol. Soc. Bot. Méx. 85:61-67.

40. R Development Core Team. 2010. R: A language and environment for statistical computing. R Foundation for Statistical Computing. Vienna, Austria. http://www.R-project.org 
41. Reid, N. 1989. Dispersal of mistletoe by honeyeaters and flowerpeckers: Components of seed dispersal quality. Ecology 70:137-145.

42. Restrepo, C. 1987. Aspectos ecológicos de la diseminación de cinco especies de muérdagos por aves. Humboldtia 1:65-116.

43. Restrepo, C., Sargent, S., Levey, D., and Watson, D. 2002. The role of vertebrates in the diversification of New World mistletoes. Pages 83-98 in: Seed Dispersal and Frugivory: Ecology, Evolution and Conservation. D. J. Levey, W. R. Silva, and M. Galetti, eds. CABI Publishing, Wallingford, Oxfordshire, UK.

44. Rödl, T., and Ward, D. 2002. Host recognition in a desert mistletoe: Early stages of development are influenced by substrate and host origin. Funct. Ecol. 16:128-134.

45. Roxburgh, L. 2005. The effect of gut processing on the quality of mistletoe seed dispersal. J. Trop. Ecol. 23:377-380.

46. Roxburgh, L., and Nicolson S. W. 2005. Patterns of host use in two African mistletoes: The importance of mistletoe-host compatibility and avian disperser behaviour. Funct. Ecol. 19:865-873.

47. Roxburgh, L., and Nicolson, S. W. 2008. Differential dispersal and survival of an African mistletoe: Does host size matter? Plant Ecol. 195:21-31.

48. Samuels, I. A., and Levey, D. J. 2005. Effects of the gut passage on seed germination: Do experiments answer the questions they ask? Funct. Ecol 19:365-368.

49. Sargent, S. 1995. Seed fate in a tropical mistletoe: The importance of host twig size. Funct. Ecol. 9:197-204.

50. Soto-Gamboa, M., and Bozinovic, F. 2002. Fruit-disperser interaction in a mistletoe-bird system: A comparison of two mechanisms of fruit processing on seed germination. Plant Ecol. 159:171-174.

51. Vázquez-Collazo, T., and Geils, B. W. 2002. Psittacanthus in Mexico. Pages 9-17 in: Mistletoes of North American Conifers. B. W. Geils, J. CibriánTovar, and B. Moody, eds. Gen. Tech. Rep. RMRS-GTR-98. U. S. Dep. Agric. For. Serv. Rocky Mountain Research Station, Ogden, UT.

52. Watson, D. 2001. Mistletoes-A keystone resource in forest and woodlands worldwide. Ann. Rev. Ecol. Syst. 32:219-249.

53. Yan, Z. 1993. Resistance to haustorial development of two mistletoe, Amyema preissi (Miq.) Tieghem and Lysiana exocarpi (Behr.) Tieghem ssp. Exocarpi (Loranthaceae), on host and nonhost species. Int. J. Plant Sci. 154:386-394.

54. Yan, Z., and Reid, N. 1995. Mistletoe (Amyema miquelii and A. pendulum) seedling establishment on eucalypt hosts in eastern Australia. J. Appl. Ecol 32:778-784. 